http://dx.doi.org/10.1590/1678-4162-9421

Arq. Bras. Med. Vet. Zootec., v.69, n.6, p.1466-1472, 2017

\title{
Insulinoma canino: relato de caso
}

[Canine insulinoma: case reports]

\author{
L. Padovani ${ }^{1}$, D.D. Silva ${ }^{1}$, J.R. Moreira ${ }^{2}$, M.J.L. Cardoso $^{3}$, G.W. Di Santis ${ }^{3}$, M.S. Zanutto ${ }^{3}$ \\ ${ }^{1}$ Aluno de pós-graduação-Universidade Estadual de Londrina - UEL- Londrina, PR \\ ${ }^{2}$ Residente - Universidade Estadual de Londrina - UEL - Londrina, PR \\ ${ }^{3}$ Universidade Estadual de Londrina - UEL - Londrina, PR
}

\begin{abstract}
RESUMO
O insulinoma é um tumor das células $\beta$ do pâncreas, que têm a função de produzir e secretar insulina e, geralmente são malignos em cães. $O$ presente trabalho descreve o diagnóstico e o manejo terapêutico de três casos de insulinoma. Os sinais clínicos dos animais relatados variaram de acordo com a severidade e a duração da hipoglicemia. O diagnóstico presuntivo se deu através dos sinais clínicos e da dosagem de insulina sérica no momento de mais intensa hipoglicemia e, o diagnóstico definitivo foi obtido por meio de exame histopatológico nos três casos relatados. $\mathrm{O}$ tratamento realizado variou de acordo com a intensidade dos sinais clínicos.
\end{abstract}

Palavras-chave: tumor, células $\beta$, hipoglicemia

\begin{abstract}
Insulinoma is a tumor of the $\beta$ cells of the pancreas, which have the function to produce and secrete insulin and are usually malignant in dogs. This paper describes the diagnosis and therapeutic management of three cases of insulinoma. The clinical signs reported animals varied according to the severity and duration of hypoglycemia. The presumptive diagnosis was based on clinical signs and serum insulin dosage at the time of hypoglycemia and more intense, the definitive diagnosis was made by histopathological examination in three of the reported cases. The treatment was varied according to the severity of clinical signs.
\end{abstract}

Keywords: tumor, $\beta$ cells, hypoglycemia

\section{INTRODUÇÃO}

Os insulinomas, também conhecidos como tumores de células $\beta$ secretores de insulina ou carcinomas de células $\beta$, são tumores funcionais de células $\beta$ do pâncreas que secretam insulina, independentemente dos efeitos supressores da hipoglicemia, e são os tumores pancreáticos endócrinos mais comuns descritos em cães (Goutal et al., 2012).

Embora outros hormônios sejam produzidos, a insulina é prevalente, e é devido ao excesso de sua produção que surgem os sinais clínicos que resultam de neuroglicopenia induzida pela hiperinsulinemia e incluem letargia, fraqueza, ataxia, mudanças de comportamento, convulsões, coma e morte. As alterações decorrentes do aumento nas concentrações de hormônios antagonistas da insulina (ex.: glucagon, catecolaminas, cortisol e hormônio de crescimento) incluem fasciculações, tremores musculares, alterações de comportamento e inquietação (Leifer et al., 1986; Hess, 2005; Goutal et al., 2012).

O diagnóstico presuntivo de insulinoma inclui a combinação dos sinais clínicos e dos exames laboratoriais e de imagem (Goutal et al., 2012; Nelson, 2015). O achado laboratorial mais consistente nesses pacientes é a hipoglicemia, que, na maioria dos casos, está abaixo de 70mg/dL (normal: $70 \mathrm{mg} / \mathrm{dL}-110 \mathrm{mg} / \mathrm{dL}$ ), e a

Recebido em 9 de setembro de 2016

Aceito em 19 janeiro de 2017

E-mail: luisapadovani1@hotmail.com 
elevação dos níveis séricos de insulina (Goutal et al., 2012; Fossum e Caplan, 2015). Os exames de imagem, particularmente o ultrassom, auxiliam o cirurgião pelas informações quanto à localização, ao tamanho, à quantidade de tumores no pâncreas e à presença de metástases (Meleo, 1990; Goutal et al., 2012). O diagnóstico definitivo de insulinoma se dá por meio dos exames citológico e histopatológico (Nelson, 2015).

O tratamento de pacientes com insulinoma pode ser cirúrgico e/ou médico, dependendo do caso (Fossum e Caplan, 2015). O prognóstico da doença varia de reservado a ruim e é influenciado pela presença de metástase, da quantidade e do tamanho dos tumores e da facilidade ou não de remoção da massa no momento do diagnóstico (Goutal et al., 2012).

O presente trabalho tem como objetivo, além de descrever os sinais clínicos, o diagnóstico e a abordagem terapêutica de três casos de insulinoma atendidos no Hospital Veterinário da Universidade Estadual de Londrina, no período de abril de 2013 a junho de 2015, contribuir para o alerta aos clínicos da suspeita diagnóstica, uma vez que a sintomatologia apresentada pelo animal é inespecífica e pode ser confundida com outras doenças.

\section{RELATO DE CASOS}

Caso 1. Uma fêmea canina, sem raça definida, 10 anos, 18 quilos, foi atendida com queixa de ataxia, êmese e um episódio convulsivo. Exame físico apresentava-se sem alterações. Os exames laboratoriais revelaram hipoglicemia $(50 \mathrm{mg} / \mathrm{dL})$. Durante o internamento, o animal apresentou quatro episódios convulsivos. Realizou-se aplicação de diazepam e bolus lento de glicose IV, pois a glicemia, durante os episódios, estava entre 29 e $38 \mathrm{mg} / \mathrm{dL}$. No mesmo momento, com o animal em jejum, foram obtidas amostras de soro para dosagem de insulina por radioimunoensaio (B.E.T. Laboratories-RJ), que revelou concentração de $13,7 \mu \mathrm{U} / \mathrm{mL}$ (normal: $5-25 \mu \mathrm{U} / \mathrm{mL}$ ) e de sangue para dosagem de glicose, que estava $30 \mathrm{mg} / \mathrm{dL}$. Iniciou-se terapia com glicocorticoide (dexametasona) durante seis horas e, após o animal foi submetido à celiotomia exploratória diante da suspeita de insulinoma. Por meio da cirurgia, visualizou-se nódulo em pâncreas (Fig. 1A, B e C), que foi retirado e encaminhado para análise citológica e histopatológica. À citologia, havia predomínio de células epiteliais, ora em agregados coesos, ora dispersas, com moderada relação núcleo:citoplasma, núcleos redondos, nucléolos inconspícuos a pequenos e únicos, citoplasma levemente basofílico, finamente vacuolizado e granular e baixo pleomorfismo celular e nuclear, o que não permitiu a diferenciação entre adenoma e carcinoma. Ao exame histopatológico, observou-se nódulo parcialmente infiltrativo inserido no parênquima pancreático, caracterizado por ninhos $\mathrm{e}$ trabéculas de células epiteliais envoltos por tecido fibrovascular delicado, o qual permeava o tecido pancreático normal e a musculatura lisa duodenal. As células apresentavam pleomorfismo discreto, citoplasma eosinofílico, granular, finamente vacuolizado, núcleos redondos e nucléolos pequenos e únicos com áreas eventuais de pleomorfismo nuclear moderado (Fig. 2A, B). A paciente veio a óbito ao final do procedimento cirúrgico, decorrente de complicações anestésicas. Não se encontrou evidência de metástases à necropsia e ao exame histopatológico. A proprietária não permitiu a abertura do crânio para remoção e avaliação encefálica.

Caso 2. Um canino, fêmea, da raça Boxer, 16 anos, 18 quilos, não castrada, foi atendido com queixa de ataxia, agitação e um episódio convulsivo. Ao exame físico, o animal apresentava nódulos em mamas e demais parâmetros sem alterações. Os exames laboratoriais revelaram apenas hipoglicemia $(30 \mathrm{mg} / \mathrm{dL})$. No atendimento, o animal apresentou convulsões focais e movimentos de pedalagem, que não cessaram com a administração de diazepam e fenobarbital. Mesmo com o início do fenobarbital, administração em bolus lento de glicose e glicocorticoide (dexametasona), a paciente apresentou mais três convulsões, que cessaram apenas com administração de propofol. Durante os episódios, a glicemia estava entre 27 e $34 \mathrm{mg} / \mathrm{dL}$. No momento da menor glicemia, foi obtida amostra de soro, com o animal em jejum, para dosagem de insulina por radioimunoensaio (B.E.T. Laboratories-RJ), que revelou concentração de $3,7 \mu \mathrm{U} / \mathrm{mL}$. No segundo dia de hospitalização, o animal veio a óbito e foi realizada necropsia que identificou nódulo de $1 \mathrm{~cm}$ de diâmetro na cabeça do pâncreas (Fig. 3A), além de neoformações em pulmão, 


\section{Padovani et al.}

miocárdio, pele e um nódulo mamário. Microscopicamente, o nódulo pancreático era bem delimitado, parcialmente infiltrativo no tecido adjacente, composto por trabéculas e ninhos celulares delimitados por estroma fibrovascular delicado (Fig. 3B). As células apresentavam citoplasma eosinofílico, levemente granular, núcleos redondos, pequenos $\mathrm{e}$ nucléolos inconspícuos (Fig. 3C). O linfonodo peripancreático estava livre de metástases. As neoformações em miocárdio e pulmão eram metástases do carcinoma mamário.
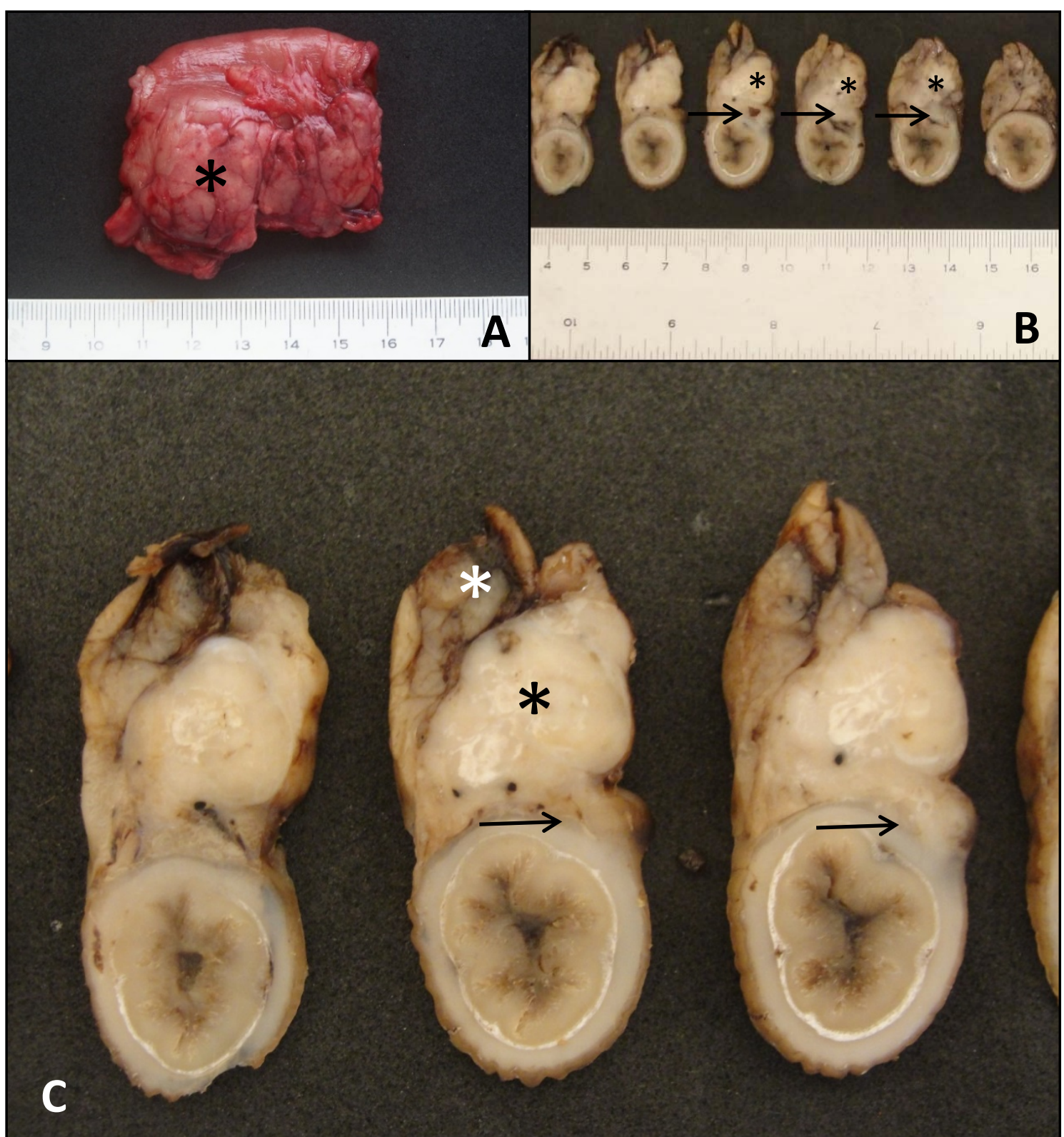

Figura 1. A) Fragmento de pâncreas e duodeno, com nódulo pancreático (*) após ressecção cirúrgica. B) Cortes transversais seriados de duodeno com infiltração neoplásica em serosa e muscular (seta) a partir de nódulo pancreático $(*)$. C) Visão aproximada dos três primeiros segmentos observados em "B", com destaque para as áreas de infiltração neoplásica na parede do duodeno (setas) oriunda do nódulo pancreático (asterisco preto) e sua relação com o pâncreas normal (asterisco branco). 


\section{Insulinoma canino...}

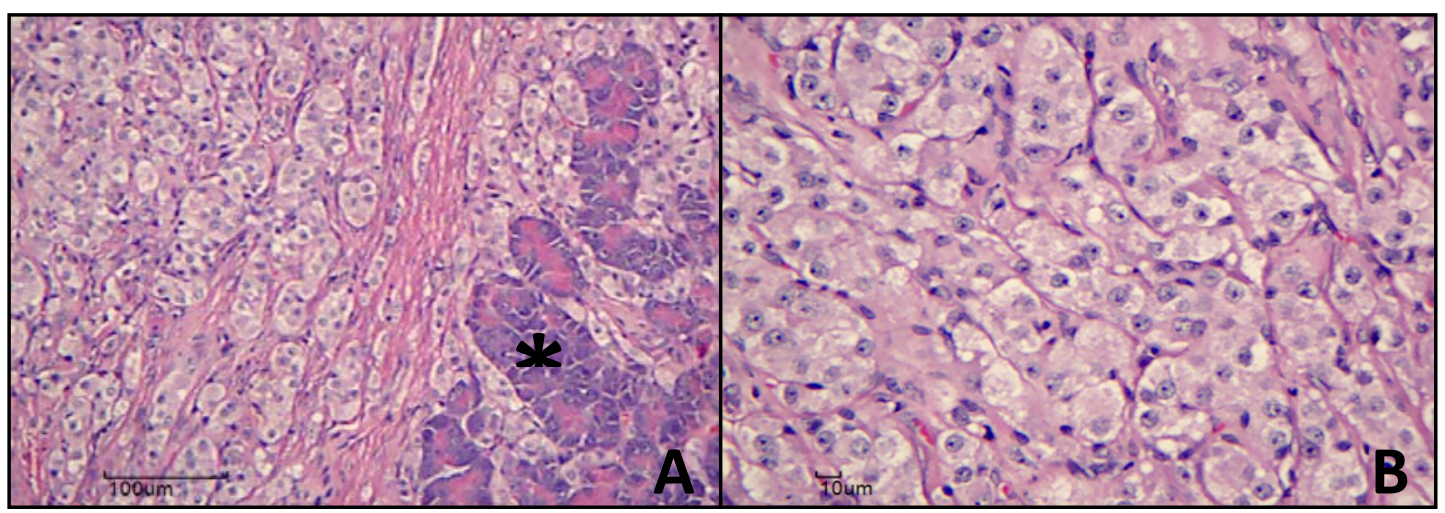

Figura 2. Cão, pâncreas, carcinoma de células $\beta$. A) Pâncreas. Ninhos e trabéculas de células epiteliais com citoplasma vacuolizado, eosinofílico permeando ácinos exócrinos (*). HE, 200x. B) Neoformação pancreática. Ninhos e trabéculas bem delimitados por tecido fibrovascular delicado, compostos por células epiteliais com pleomorfismo celular e nuclear discretos, núcleos redondos com nucléolos geralmente presentes, únicos e pequenos (setas). HE, 400x.

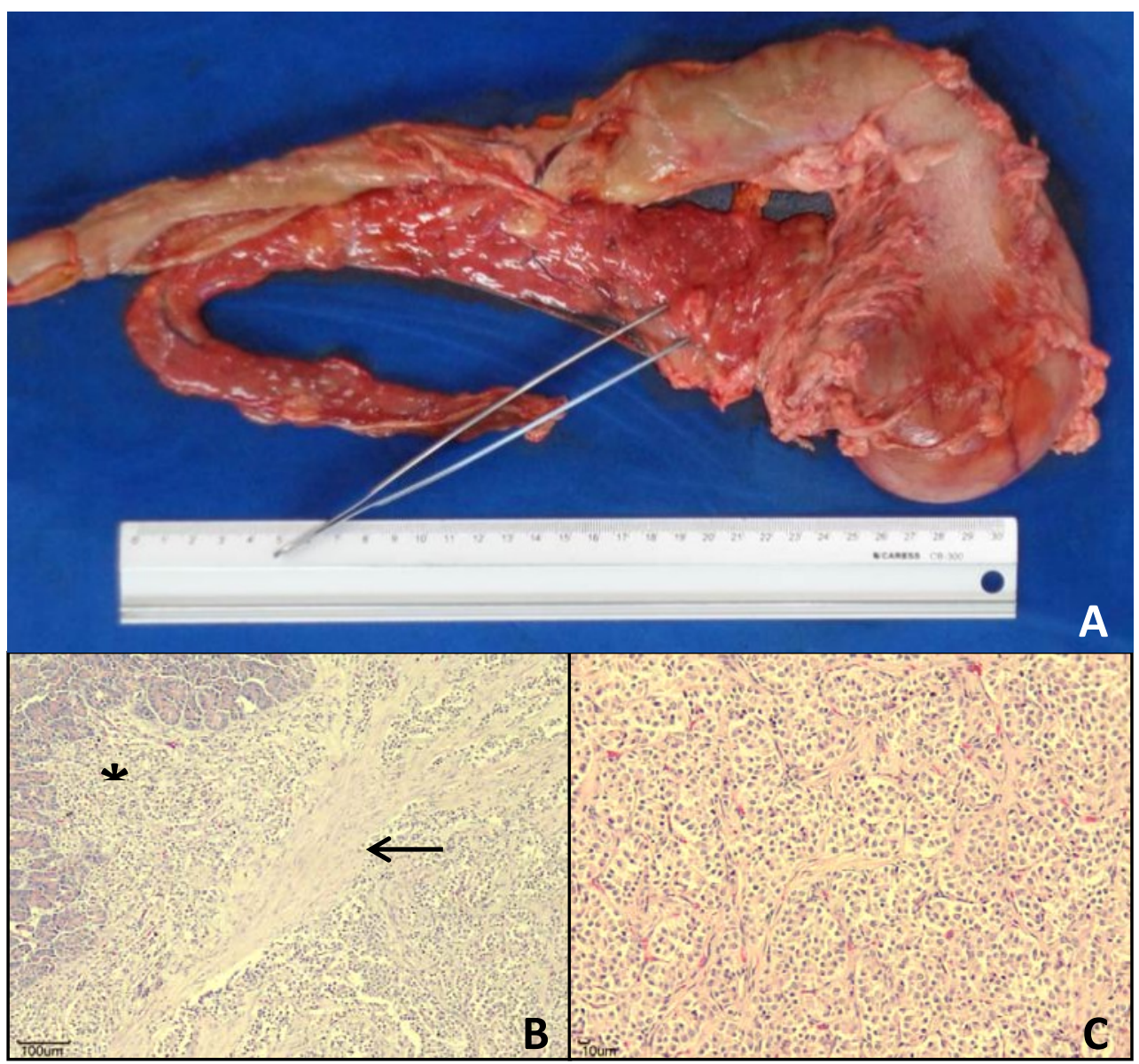

Figura 3. Cão, pâncreas, carcinoma de células $\beta$. A) Discreta neoformação circular, esbranquiçada, protruindo do parênquima pancreático. B) Observa-se neoformação infiltrando o estroma pancreático $(*)$ a partir de uma cápsula fibrosa que delimita parcialmente o tumor (seta). HE, 100x. C) Neoformação caracterizada por ninhos de células epiteliais com citoplasma eosinofílico e núcleos redondos, delimitados por septos fibrovasculares. HE, 200x. 
Caso 3. Um canino, fêmea, da raça Cocker Americano, 13 anos, 14,3 quilos, castrada, foi atendido com queixa de convulsões e fraqueza intermitentes com evolução de dois meses. Ao exame físico, o animal apresentava nódulos mamários e demais parâmetros normais. Os exames laboratoriais revelaram apenas hipoglicemia $(25 \mathrm{mg} / \mathrm{dL})$. O animal foi internado para monitoração e foi coletado sangue, com ele em jejum, simultaneamente para dosagem sérica de insulina por radioimunoensaio (B.E.T.Laboratories-RJ) e de glicose, que revelaram concentração de $36 \mu \mathrm{U} / \mathrm{mL}$ e $28 \mathrm{mg} / \mathrm{dL}$, respectivamente. Ao exame ultrassonográfico, não foram detectadas alterações. Foi iniciado o tratamento médico com glicocorticoide diante da suspeita de insulinoma (prednisona - na dose inicial de $0,5 \mathrm{mg} / \mathrm{kg}$, via oral), três vezes ao dia. Durante o tratamento, o animal foi submetido à mastectomia unilateral direita. A dose do corticoide foi reduzida gradualmente até $0,17 \mathrm{mg} / \mathrm{kg}$ de prednisona, uma vez ao dia, e o animal se manteve sem sinais clínicos em decorrência da hipoglicemia até junho de 2015, um ano e seis meses após o diagnóstico presuntivo de insulinoma, quando retornou ao HV-UEL com queixa de convulsão. Durante o internamento, mesmo com o tratamento instituído, as convulsões não cessaram e o proprietário optou pela eutanásia. $\mathrm{O}$ animal foi submetido à necropsia, quando foi visualizado tumor único, firme e irregular em pâncreas, tumores em mamas e nódulos em fígado e pulmões. Histologicamente, observou-se neoformação em pâncreas, parcialmente encapsulada, caracterizada por ninhos de células epiteliais moderadamente dispersas, delimitados por estroma fibrovascular moderado (Fig. 4A). As células apresentavam citoplasma eosinofílico, finamente granular, núcleos redondos e nucléolos inconspícuos. $\mathrm{O}$ linfonodo peripancreático apresentava infiltração neoplásica acentuada (Fig. 4B), assim como o fígado. As neoformações pulmonares eram metástases de carcinoma mamário. O encéfalo apresentava edemas perivascular e perineuronal moderados, além de vacuolização moderada do neurópilo.

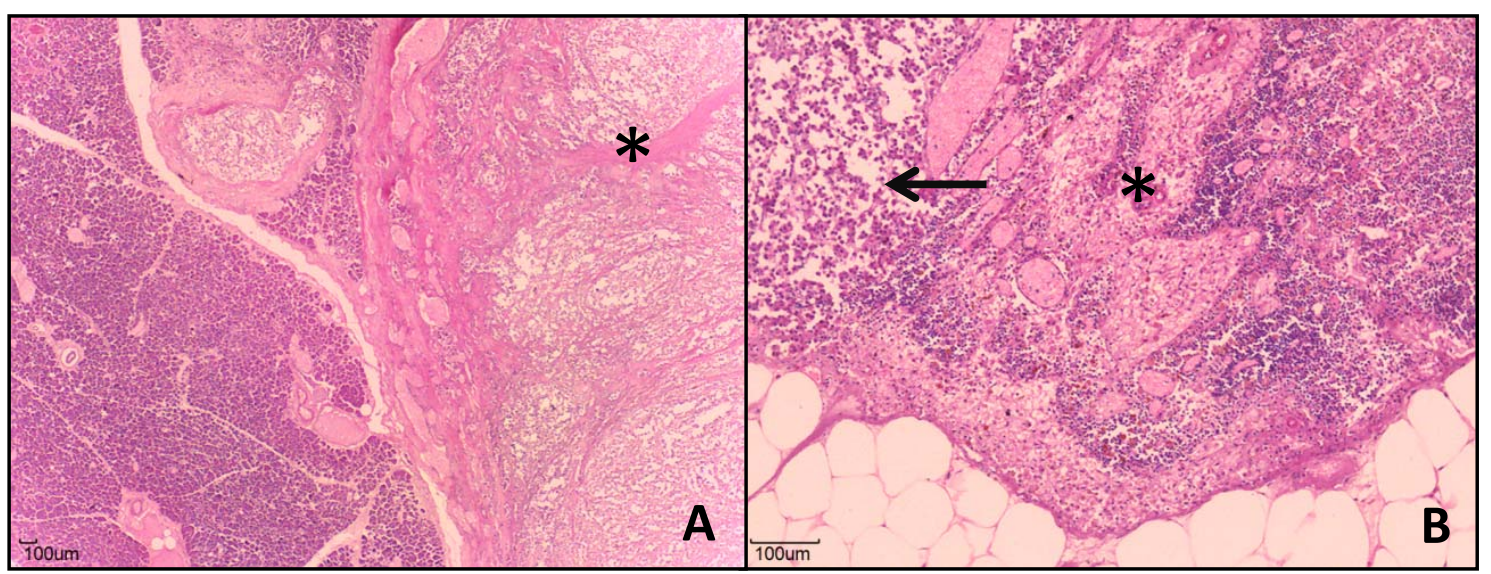

Figura 4. Cão, pâncreas, carcinoma de células $\beta$. A) Neoformação pancreática (*) delimitada e septada por tecido fibrovascular espesso produzindo um aspecto lobulado no menor aumento. HE, 25x. B) Linfonodo peripancreático $\left(^{*}\right)$ parcialmente substituído pelo tecido neoplásico (seta). HE, 100x.

\section{DISCUSSÃO}

As pacientes, diagnosticadas com insulinoma, apresentavam porte médio a grande e idade acima de nove anos. A idade média de apresentação da doença está entre 8,5 e 10 anos de idade (Ellie e Zerbe, 1996; Nelson, 2015). Os cães de raças médias a grandes são mais acometidos, com peso corporal médio acima de
25 quilos (Steiner e Bruyette, 1996; Nelson, 2015).

O exame físico raramente apresenta alterações significativas, a menos que esses pacientes apresentem sinais devido às obstruções pelo tumor primário ou às metástases (Goutal et al., 2012). As pacientes apresentavam como principal sinal clínico episódios convulsivos, e, ao exame físico, não foram notadas alterações 
relacionadas diretamente ao insulinoma. Clinicamente, é importante associar a presença de hipoglicemia com a elevação dos níveis séricos de insulina e a presença de neoplasia de células $\beta$ (Goutal et al., 2012; Nelson, 2015). A hipoglicemia frequente, verificada durante $\mathrm{o}$ internamento, é o achado laboratorial mais comum nesses pacientes (Goutal et al., 2012). Os sinais clínicos, descritos anteriormente, nos casos de insulinoma, são decorrentes da hipoglicemia induzida pela hiperinsulinemia, porém, mesmo com a queda nos valores da glicemia, alguns animais com insulinoma não apresentam sinais clínicos, pois eles se adaptam à hipoglicemia crônica durante determinado período de tempo (Leifer et al.,1986; Goutal et al., 2012).

O soro foi coletado, em jejum, após verificação de hipoglicemia intensa e sustentada para a mensuração da insulina. $\mathrm{O}$ resultado da concentração de insulina sérica variou entre os casos relatados. Quando a concentração de insulina sérica está acima de $20 \mu \mathrm{U} / \mathrm{mL}(5 \mu \mathrm{U} / \mathrm{mL}$ $-25 \mu \mathrm{U} / \mathrm{mL}$ ), interpreta-se como alta a probabilidade do insulinoma; quando está entre $10-20 \mu \mathrm{U} / \mathrm{mL}$, há possibilidade de ser tumor de células $\beta$; entre $5-10 \mu \mathrm{U} / \mathrm{mL}$, há pouca chance de confirmar o diagnóstico; e abaixo de $5 \mu \mathrm{U} / \mathrm{mL}$, é descartada a suspeita de insulinoma (Nelson, 2015), porém, no caso 2 relatado, a concentração de insulina sérica estava abaixo de $5 \mu \mathrm{U} / \mathrm{mL}$ e o exame histopatológico confirmou o tumor de pâncreas. A concentração da insulina do caso 2 foi incompatível com a suspeita clínica de insulinoma, o que pode ser explicado pelo aumento do fator de crescimento semelhante à insulina tipo-1 (IGF-1), que é produzido em resposta ao hormônio de crescimento $(\mathrm{GH})$ e que também reduz a glicemia (Buishand et al., 2012). Em pacientes hígidos, os níveis de insulina sérica devem estar abaixo do normal ou indetectáveis $(<5 \mu \mathrm{U} / \mathrm{mL})$ quando a glicose sanguínea for inferior a $60 \mathrm{mg} / \mathrm{dL}$ (Goutal et al., 2012). O diagnóstico presuntivo pôde, assim, ser estabelecido pela demonstração de aumento nos níveis de insulina inapropriados associados à hipoglicemia nos dois outros casos relatados.

O exame ultrassonográfico pode ser utilizado para detectar presença de massa em pâncreas em muitos casos, além de detectar presença de metástase (Nelson, 2015). Nos dois primeiros casos, diante da gravidade do quadro, não houve tempo hábil para o encaminhamento do exame.
Clinicamente, o termo insulinoma se refere a tumores de células $\beta$, independentemente da sua malignidade. Histologicamente, o insulinoma pode ser classificado como adenoma ou carcinoma de células $\beta$, considerando-se os critérios que determinem sua malignidade (Capen, 2002).

A escolha do tratamento, médico e/ou cirúrgico foi determinada de acordo com a gravidade dos sinais clínicos, a opção dos proprietários e os exames de imagem (Tobin et al., 1999). A paciente do primeiro relato possuía um nódulo único no pâncreas, que foi retirado completamente durante a cirurgia. Caso ela sobrevivesse, haveria chance de cura e melhor prognóstico (Fossum e Caplan, 2015). O tratamento médico com dextrose por via intravenosa deve ser iniciado durante as crises de hipoglicemia. Como os tumores de células $\beta$, embora secretem insulina independentemente dos efeitos supressores da hipoglicemia, não são completamente autônomos e respondem a estímulos (ex.: glicose) com a secreção de insulina em quantidades excessivas, a administração de dextrose deve ser lenta e cautelosa. Após a estabilização dos sinais clínicos, mantém-se fluidoterapia com dextrose 5\% (Leifer et al., 1986; Meleo, 1990; Goutal et al., 2012). Os glicocorticoides também podem ser usados, pois antagonizam os efeitos da insulina por sua ação hiperglicemiante. Para $o$ tratamento dos sinais crônicos associados ao insulinoma, são utilizados medicamentos como prednisona, diazoxido e octreotide (Goutal et al., 2012; Nelson, 2015). Os tumores de células $\beta$ geralmente são malignos, e os locais mais comuns de metástase são o fígado e os linfonodos (Goutal et al., 2012). A paciente do segundo caso apresentava metástase em linfonodo regional e no fígado, porém as metástases pulmonares nos casos 2 e 3 eram ambas de carcinomas mamários.

\section{CONCLUSÕES}

O insulinoma é um tumor de pâncreas endócrino, geralmente maligno. Embora não tenham estudos que revelem a prevalência da doença em cães, sabe-se que a taxa de mortalidade é alta e que a intervenção médica e/ou cirúrgica deve ser a mais rápida possível a partir do diagnóstico da doença. Diante do quadro clínico característico, mesmo que a concentração de insulina sérica não 
esteja alta no momento da constatação da hipoglicemia, não se deve descartar a possibilidade de insulinoma, e o exame histopatológico deve ser realizado.

\section{REFERÊNCIAS}

BUISHAND, F.O.; VAN ERP, M.G.M.; GROENVELD, H.A. et al. Expression of insulin-like growth factor -1 by canine insulinomas and their metastases. Vet. J., v.191, p.334-340, 2012.

CAPEN, C.C. Tumors of the endocrine glands. In: MEUTEN, D.J. (Ed.). Tumors in domestic animals. 4.ed. Iowa: Iowa State Press, 2002. p.607-664.

ELLIE, M.S., ZERBE, C.A. Insulinoma in dogs, cats and ferrets. Compend. Contin. Educ. Vet., v.18, p.13-25, 1996.

FOSSUM, T.W.; CAPLAN, E.R. Surgery of the pancreas. In: FOSSUM T.W. Small animal surgery. 4.ed. St Louis: Mosby Elsevier, 2015. p.660-664.

GOUTAL, C.M.; BRUGMANN, B.L.; RYAN, K.A. Insulinoma in dogs: a review. Anim. Hosp. Assoc., v.48, p.151-163, 2012.
HESS, R.S. Insulin secreting islet cell neoplasia. In: ETTINGER, S.J.; FELDMAN, E.C. (Eds.). Textbook of veterinary internal medicine. 6.ed. Philadelphia: Saunders Elsevier, 2005. p.15601563.

LEIFER, C.E.; PETERSON, M.E.; MATUS, R.E. Insulin-secreting tumor: diagnosis and medical and surgical management in 55 dogs. $J$. Am. Vet. Med. Assoc., v.188, p.60-64, 1986.

MELEO, K. Management of insulinoma patients with refractory hypoglycemia. Probl. Vet. Med., v.2, p.602-609, 1990.

NELSON, R.W. Beta cell neoplasia: insulinoma. In: FELDMAN, E.C.; NELSON, R.W.; REUSCHA, C.E. et al. (Eds.). Canine and feline endocrinology. 4.ed. St Louis: Saunders Elsevier, 2015. p.348-375.

STEINER, J.M.; BRUYETTE, D.S. Canine insulinoma. Compend. Contin. Educ. Vet., v.18, p.13-25, 1996.

TOBIN, R.L.; NELSON, R.W.; LUCROY, M.D. et al. Outcome of surgical versus medical treatment of dogs with beta cell neoplasia: 39 cases (1990-1997). J. Am. Med. Vet. Assoc., v.215, p.226-230, 1999. 